\title{
PENERAPAN HUKUM DE MOIVRE PADA PENENTUAN NILAI CADANGAN PREMI ASURANSI JIWA JOINT LIFE
}

\author{
Rizka Aulia Novalinda $^{1 \S}$, I Nyoman Widana ${ }^{2}$, Ketut Jayanegara ${ }^{3}$ \\ ${ }^{1}$ Program Studi Matematika, Fakultas MIPA- Universitas Udayana [Email: rizka261199@gmail.com] \\ ${ }^{2}$ Program Studi Matematika, Fakultas MIPA- Universitas Udayana [Email: nwidana@yahoo.com] \\ ${ }^{3}$ Program Studi Matematika, Fakultas MIPA- Universitas Udayana [Email: ktjayanegara@unud.ac.id] \\ ${ }^{\S}$ Corresponding Author
}

\begin{abstract}
Joint life insurance is a single policy that covers two lives. The benefit is paid out when the first person dies. Insurance companies need to calculate and assign premiums and a policy value in order to know. the expected value of the future loss. The study used the quantitative data of mortality for men and women obtained from the Indonesian Mortality Table (TMI) 2011. Data analysis techniques use the New Jersey method of prospects and a legal approach of mortality that is De Moivre's law. The purpose of this study is to determine policy value on joint life insurance that applies to De Moivre's laws and compare policy value on joint life insurance that applies De Moivre's laws and without the application of De Moivre's laws. Research shows that joint life insurance policy value with New Jersey methods of prospective and application of De Moivre's law always come into value smaller than those without an application of De Moivre's law, but at the end of period both are worth the same according to the value of their benefits.
\end{abstract}

Keywords: Joint Life Insurance, Policy Value, New Jersey Method, De Moivre's Law

\section{PENDAHULUAN}

Peristiwa kematian seseorang tentu memberikan dampak yang sangat besar terhadap keluarga yang ditinggalkan. Asuransi jiwa sangat diperlukan agar risiko yang akan dihadapi manusia dapat diminimumkan. Futami (1994) menyampaikan bahwa menurut jumlah pihak pemegang polisnya, terdapat dua jenis asuransi jiwa yakni asuransi perorangan dan asuransi kumpulan. Asuransi kumpulan dapat terbagi atas asuransi joint life serta asuransi last survivor. Asuransi joint life sangat memberikan manfaat untuk pelindung keuangan pasangan, bila satu dari pihak tertanggung meninggal semasa jangka waktu kontrak maka pasangan akan mendapatkan biaya pertanggungan.

Perusahaan asuransi diharuskan dapat menghadapi klaim biaya pertanggungan yang kapanpun dapat diajukan oleh pihak pemegang polis. Dana dari himpunan premi yang dibayar pemegang polis akan menjadi pembentuk utama cadangan asuransi. Cadangan diperlukan karena apabila terdapat kerugian aktual dalam pertahun bisa tertutupi oleh cadangan tersebut, tanpa perlu meningkatkan tarif premi (Hasrullah, 2019).

Terdapat beberapa penelitian terdahulu perihal penentuan cadangan premi, pertama menurut Tewo et al. (2018), nilai cadangan premi asuransi joint life menggunakan metode New Jersey selalu lebih kecil dibandingkan cara prospektif. Menurut Fibrianti (2016), Hukum De Moivre dapat dipergunakan dalam menentukan cadangan premi. Menurut Finan (2011), Hukum De Moivre adalah satu diantara hukum mortalitas pada aktuaria yang diperoleh dari distribusi seragam. Hukum De Moivre dimanfaatkan sebagai penetapan percepatan mortalitas, fungsi kepadatan peluangnya bisa juga digunakan untuk penetapan peluang meninggal serta peluang hidup seseorang.

Dalam artikel ini akan ditentukan cadangan premi pada asuransi joint life yang menerapkan hukum De Moivre serta perbandingan nilai cadangan premi asuransi joint life yang menerapkan hukum De Moivre dan tanpa penerapan hukum De Moivre. Tingkat suku 
bunga 3,5\% dipergunakan dalam tulisan ini, penentuan cadangan premi asuransi jiwa joint life pada penelitian ini diterapkan metode New Jersey cara prospektif. Penelitian ini memiliki tujuan untuk menentukan cadangan premi pada asuransi joint life yang menerapkan hukum De

Moivre serta perbandingan nilai cadangan premi asuransi joint life yang menerapkan hukum De Moivre dan tanpa penerapan hukum De Moivre.

Menurut Bowers et al. (1997), hubungan antara fungsi survival dengan hukum De Moivre adalah:

$$
S(x)=\frac{\omega-x}{\omega}=1-\frac{x}{\omega}
$$

sehingga peluang hidup peserta asuransi berdasarkan hukum De Moivre adalah:

$$
\begin{gathered}
{ }_{n} p_{x}=\frac{\omega-x-n}{\omega-x} \\
p_{x+n}=\frac{\omega-x-n-1}{\omega-x-n}
\end{gathered}
$$

dan peluang meninggal peserta asuransi berdasarkan hukum De Moivre adalah :

$$
\begin{gathered}
{ }_{n} q_{x}=\frac{n}{\omega-x} \\
q_{x+n}=\frac{1}{\omega-x-n}
\end{gathered}
$$

Menurut Futami (1994), nilai anuitas hidup akhir asuransi joint life, jangka waktu n tahun bagi peserta asuransi yang dibayarkan sejumlah 1 rupiah dapat dinotasikan oleh :

$$
a_{x y: \bar{n} \mid}=\sum_{m=1}^{n} v_{m}^{m} p_{x y}
$$

Sedangkan Nilai dari anuitas hidup awal asuransi joint life dinotasikan sebagai :

$$
\ddot{a}_{x y: \overline{n \mid}}=\sum_{m=0}^{n-1} v_{m}^{m} p_{x y}
$$

Premi tunggal asuransi jiwa dwiguna joint life seumur hidup adalah :

$$
A_{x y}=\sum_{m=0}^{\infty} v^{m+1}{ }_{m} p_{x y} q_{x+m, y+m}
$$

Premi tunggal asuransi jiwa dwiguna joint life berjangka $n$ tahun adalah :

$$
A_{x y: \bar{n} \mid}=1-d \ddot{a}_{x y: \bar{n} \mid}
$$

Premi tahunan asuransi joint life dwiguna dengan jangka waktu $n$ tahun adalah :

$$
P_{x y: \overline{n \mid}}=\frac{A_{x y: \overline{n \mid}}}{\ddot{a}_{x y \overline{n n}}}
$$

Premi tahunan asuransi jiwa joint life dwiguna seumur hidup untuk masa pembayaran $\mathrm{h}$ kali dinotasikan oleh :

$$
{ }_{h} P_{x y}=\frac{A_{x y}}{\ddot{a}_{x y: \bar{\eta} \mid}}
$$

Cadangan premi metode prospektif tahun ke- $t$ bagi asuransi joint life dwiguna, jangka waktu $n$ tahun dan premi dibayarkan pada awal tahun adalah :

$$
{ }_{t} V_{x y: \overline{n \mid}}=A_{x+t, y+t: \overline{n-t \mid}}-P_{x y: \overline{n \mid}} \ddot{a}_{x+t, y+t: \overline{n-t \mid}}
$$

Menurut Sembiring (1986), metode New Jersey dipergunakan apabila polis memiliki premi bersih tahunan dengan 20 kali pembayaran premi untuk asuransi seumur hidupnya lebih besar dari premi bersih tahunan berjangka, namun premi kotor lebih besar dari $1,5 \frac{C_{x}}{D_{x}}$. Cadangan akhir pada tahun pertama metode New Jersey adalah nol, maka :

$$
\begin{gathered}
\alpha^{J}=\frac{C_{x}}{D_{x}} \\
\beta^{J}=P_{x: \overline{n \mid}}+\frac{P_{x: \overline{n \mid}}-\alpha^{J}}{a_{x: \overline{19}}}
\end{gathered}
$$

\section{METODE PENELITIAN}

Jenis data kuantitatif yang digunakan dalam penelitian ini adalah data peluang kematian untuk laki-laki dan perempuan yang diperoleh dari Tabel Mortalitas Indonesia (TMI) tahun 2011. Penentuan cadangan premi asuransi jiwa joint life pada penelitian ini, digunakan metode New Jersey dan diterapkan hukum De Moivre. Adapun langkah-langkah penelitiannya yaitu :

1. Penentuan nilai anuitas hidup berjangka awal dan akhir asuransi joint life menerapkan hukum De Moivre.

2. Penentuan premi bersih tunggal berjangka asuransi joint life menerapkan hukum De Moivre.

3. Penentuan premi bersih tahunan berjangka asuransi joint life menerapkan hukum De Moivre.

4. Penentuan premi bersih tunggal asuransi joint life seumur hidup menerapkan hukum De Moivre kemudian penentuan premi bersih tahunan asuransi joint life seumur hidup, pembayaran premi selama $h$ kali menerapkan hukum De Moivre. 
5. Penentuan premi bersih lanjutanasuransi joint life menerapkan metode New Jersey dan hukum De Moivre.

6. Penentuan cadangan premi metode $\mathrm{New}$ Jersey dan menerapkan hukum De Moivre.

7. Pengimplementasian pada contoh kasus.

8. Interpretasi hasil.

\section{HASIL DAN PEMBAHASAN}

\subsection{Penentuan Anuitas Hidup, Premi}

Tunggal dan Tahunan Berjangka Asuransi Jiwa Joint Life Berdasarkan Hukum De Moivre

Nilai anuitas hidup berjangka akhir asuransi joint life yang menerapkan hukum De Moivre dapat dinyatakan oleh :

$$
\begin{aligned}
a_{x y \bar{n} \mid} & =\sum_{m=1}^{n} v_{m}^{m} p_{x y} \\
& =\sum_{m=1}^{n} v^{m}\left(\frac{\omega-x-m}{\omega-x}\right)\left(\frac{\omega-y-m}{\omega-y}\right)
\end{aligned}
$$

Nilai anuitas hidup berjangka awal asuransi joint life yang menerapkan hukum De Moivre dapat dinyatakan oleh:

$$
\begin{aligned}
\ddot{a}_{x y \bar{n} \mid} & =\sum_{m=0}^{n-1} v^{m}{ }_{m} p_{x y} \\
& =\sum_{m=0}^{n-1} v^{m}\left(\frac{\omega-x-m}{\omega-x}\right)\left(\frac{\omega-y-m}{\omega-y}\right)
\end{aligned}
$$

Premi bersih tunggal berjangka asuransi jiwa joint life yang menerapkan hukum De Moivre dapat dinyatakan oleh :

$$
\begin{aligned}
A_{x y \overline{: n \mid}} & =1-d \ddot{a}_{x y \bar{n} \mid} \\
& =1-d\left(\sum_{m=0}^{n-1} v^{m}\left(\frac{\omega-x-m}{\omega-x}\right)\left(\frac{\omega-y-m}{\omega-y}\right)\right)
\end{aligned}
$$

Premi bersih tahunan berjangka asuransi joint life dengan menerapkan hukum De Moivre yaitu :

$$
\begin{aligned}
P_{x y \overline{: n \mid}} & =\frac{A_{x y \bar{n} \mid}}{\ddot{a}_{x y \bar{n} \mid}} \\
& =\frac{1-d\left(\sum_{m=0}^{n-1} v^{m}\left(\frac{\omega-x-m}{\omega-x}\right)\left(\frac{\omega-y-m}{\omega-y}\right)\right)}{\sum_{m=0}^{n-1} v^{m}\left(\frac{\omega-x-m}{\omega-x}\right)\left(\frac{\omega-y-m}{\omega-y}\right)}
\end{aligned}
$$

Premi bersih tunggal asuransi joint life seumur hidup dengan menerapkan hukum $D e$ Moivre yaitu :

$$
\begin{aligned}
A_{x y}= & \sum_{m=0}^{\infty} v^{m+1}{ }_{m} p_{x y} q_{x+m, y+m} \\
= & \sum_{m=0}^{\infty} v^{m+1}{ }_{m} p_{x} p_{y}\left(1-p_{x+m, y+m}\right) \\
= & \sum_{m=0}^{\infty} v^{m+1}\left(\frac{\omega-x-m}{\omega-x}\right)\left(\frac{\omega-y-m}{\omega-y}\right) \\
& \left(1-\left(\frac{\omega-x-m-1}{\omega-x-m}\right)\left(\frac{\omega-y-m-1}{\omega-y-m}\right)\right)
\end{aligned}
$$

Premi bersih tahunan asuransi joint life seumur hidup dengan masa pembayaran premi selama $\mathrm{h}$ kali berdasarkan hukum De Moivre yaitu :

$$
\begin{aligned}
& { }_{h} P_{x y}=\frac{A_{x y}}{\ddot{a}_{x y: \bar{~}}} \\
& =\frac{\sum_{m=0}^{\infty} v^{m+1}\left(\frac{\omega-x-m}{\omega-x}\right)\left(\frac{\omega-y-m}{\omega-y}\right)\left(1-\left(\frac{\omega-x-m-1}{\omega-x-m}\right)\left(\frac{\omega-y-m-1}{\omega-y-m}\right)\right)}{\sum_{m=0}^{h-1} v^{m}\left(\frac{\omega-x-m}{\omega-x}\right)\left(\frac{\omega-y-m}{\omega-y}\right)}
\end{aligned}
$$

\subsection{Penentuan Premi Lanjutan Asuransi Joint Life Menerapkan Metode New Jersey dan Hukum De Moivre}

Premi bersih lanjutan asuransi joint life berdasarkan hukum De Moivre yaitu :

$$
\begin{aligned}
\alpha^{J}= & \frac{C_{x y}}{D_{x y}} \\
& =v\left(1-\frac{\omega-x-1}{\omega-x} \frac{\omega-y-1}{\omega-y}\right) \\
\beta^{J}= & P_{x y: \bar{n} \mid}+\frac{P_{x y: \bar{n} \mid}-\alpha^{J}}{a_{x y: \overline{19}}} \\
= & \frac{1-d\left(\sum_{m=0}^{n-1} v^{m}\left(\frac{\omega-x-m}{\omega-x}\right)\left(\frac{\omega-y-m}{\omega-y}\right)\right)}{\sum_{m=0}^{n-1} v^{m}\left(\frac{\omega-x-m}{\omega-x}\right)\left(\frac{\omega-y-m}{\omega-y}\right)}+ \\
& \frac{\left\{\frac{1-d\left(\sum_{m=0}^{n-1} v^{m}\left(\frac{\omega-x-m}{\omega-x}\right)\left(\frac{\omega-y-m}{\omega-y}\right)\right)}{\sum_{m=0}^{n-1} v^{m}\left(\frac{\omega-x-m}{\omega-x}\right)\left(\frac{\omega-y-m}{\omega-y}\right)}\right\}}{\sum_{m=1}^{19} v^{m}\left(\frac{\omega-x-m}{\omega-x}\right)\left(\frac{\omega-y-m}{\omega-y}\right)} \\
& -\frac{v\left(1-\frac{\omega-x-1}{\omega-x} \frac{\omega-y-1}{\omega-y}\right)}{\sum_{m=1}^{19} v^{m}\left(\frac{\omega-x-m}{\omega-x}\right)\left(\frac{\omega-y-m}{\omega-y}\right)}
\end{aligned}
$$




\subsection{Penentuan Cadangan Premi Metode New Jersey dan Menerapkan Hukum De Moivre}

Cadangan cara prospektif metode new jersey asuransi joint life berdasarkan hukum De Moivre dapat dinyatakan sebagai:

$$
\begin{aligned}
{ }_{t} V_{x y: \bar{n} \mid}= & A_{x+t, y+t: \overline{n-t \mid}}-\left(\beta^{J}-P_{x y: \bar{n} \mid}\right) \\
& \ddot{a}_{x+t, y+t: \overline{20-t \mid}}-P_{x y: \overline{n \mid}} \ddot{a}_{x+t, y+t: \overline{n-t \mid}}
\end{aligned}
$$

dengan :

$$
\begin{aligned}
& A_{x+t, y+t: \overline{n-t \mid}}=1-d\left(\sum_{m=0}^{n-t-1} v^{m}\left(\frac{\omega-x+t-m}{\omega-x+t}\right)\left(\frac{\omega-y+t-m}{\omega-y+t}\right)\right) \\
& \beta^{J}=\frac{1-d\left(\sum_{m=0}^{n-1} v^{m}\left(\frac{\omega-x-m}{\omega-x}\right)\left(\frac{\omega-y-m}{\omega-y}\right)\right)}{\sum_{m=0}^{n-1} v^{m}\left(\frac{\omega-x-m}{\omega-x}\right)\left(\frac{\omega-y-m}{\omega-y}\right)}+ \\
& \frac{\left\{\frac{1-d\left(\sum_{m=0}^{n-1} v^{m}\left(\frac{\omega-x-m}{\omega-x}\right)\left(\frac{\omega-y-m}{\omega-y}\right)\right)}{\sum_{m=0}^{n-1} v^{m}\left(\frac{\omega-x-m}{\omega-x}\right)\left(\frac{\omega-y-m}{\omega-y}\right)}\right\}}{\sum_{m=1}^{19} v^{m}\left(\frac{\omega-x-m}{\omega-x}\right)\left(\frac{\omega-y-m}{\omega-y}\right)} \\
& -\frac{v\left(1-\frac{\omega-x-1}{\omega-x} \frac{\omega-y-1}{\omega-y}\right)}{\sum_{m=1}^{19} v^{m}\left(\frac{\omega-x-m}{\omega-x}\right)\left(\frac{\omega-y-m}{\omega-y}\right)} \\
& P_{x y: \bar{n} \mid}=\frac{1-d\left(\sum_{m=0}^{n-1} v^{m}\left(\frac{\omega-x-m}{\omega-x}\right)\left(\frac{\omega-y-m}{\omega-y}\right)\right)}{\sum_{m=0}^{n-1} v^{m}\left(\frac{\omega-x-m}{\omega-x}\right)\left(\frac{\omega-y-m}{\omega-y}\right)} \\
& \ddot{a}_{x+t, y+t: \overline{20-t \mid}}=\sum_{m=0}^{20-t-1} v^{m}\left(\frac{\omega-x+t-m}{\omega-x+t}\right)\left(\frac{\omega-y+t-m}{\omega-y+t}\right) \\
& \ddot{a}_{x+t, y+t: \overline{n-t \mid}}=\sum_{m=0}^{n-t-1} v^{m}\left(\frac{\omega-x+t-m}{\omega-x+t}\right)\left(\frac{\omega-y+t-m}{\omega-y+t}\right)
\end{aligned}
$$

\subsection{Implementasi Pada Contoh Kasus}

Diberikan asumsi-asumsi berikut sebagai contoh kasus, umur peserta saat mendaftarkan asuransi adalah ( $x$ ) 45 tahun dan (y) 40 tahun, untuk produk asuransi berjangka 30 tahun. Nilai santunan ( $S$ ) adalah Rp.100.000.000,00 serta premi kotor adalah Rp.5.000.000,00 pada tingkat suku bunga 3,5\%. Perkiraan usia maksimal untuk peserta yaitu 111 tahun. Langkah pertama adalah menentukan faktor diskon dan tingkat diskon maka :

$$
\begin{gathered}
v=\frac{1}{(1+i)}=\frac{1}{(1+0,035)}=0,96618 \\
d=1-v=0,03382
\end{gathered}
$$

\subsubsection{Cadangan Cara Prospektif dengan Metode New Jersey}

Pertama akan ditentukan nilai anuitas hidup berjangka awal dengan $n=30$ dan $n=$ 20 diperoleh sebagai berikut :

$$
\begin{aligned}
\ddot{a}_{45,40: \overline{30 \mid}} & =\sum_{m=0}^{29} v_{m}^{m} p_{45,40} \\
& =1+0,96239+\cdots+0,19007 \\
& =16,53034 \\
\ddot{a}_{45,40: \overline{20 \mid}} & =\sum_{m=0}^{19} v_{m}^{m} p_{45,40} \\
& =1+0,96239+\cdots+0,40760 \\
& =13,70063
\end{aligned}
$$

Nilai premi tunggal, premi tahunan dan premi natural asuransi jiwa joint life selama 30 tahun, diperoleh :

$$
\begin{aligned}
& A_{45,40 \overline{30 \mid}}=1-d \ddot{a}_{45,40: \overline{30 \mid}} \\
& =1-0,03382(16,53034) \\
& =0,44100 \\
& P_{45,40: \overline{30 \mid}}=\frac{A_{45,40 \overline{30 \mid}}}{\ddot{a}_{45,40: \overline{30 \mid}}}=0,02668
\end{aligned}
$$

Nilai premi tunggal asuransi jiwa joint life seumur hidup diperoleh :

$$
\begin{aligned}
A_{45,40} & =\sum_{m=0}^{\infty} v_{m}^{m+1}{ }_{m} p_{45,40} q_{45+m, 40+m} \\
& =(0,00379)+(0,00412)+\cdots \\
& =0,40182
\end{aligned}
$$

Premi tahunan dengan 20 kali pembayaran premi untuk asuransi joint life seumur hidup diperoleh :

$$
{ }_{20} P_{45,40}=\frac{A_{45,40}}{\ddot{a}_{45,40: 20 \mid}}=\frac{0,40182}{13,70063}=0,02933
$$

Premi natural asuransi joint life dengan substitusikan nilai $p_{45}=0,99721$ dan $p_{40}=$ 0,99886 pada tabel mortalita TMI 2011 diperoleh :

$$
\begin{aligned}
& \alpha^{J}=\frac{C_{45,40}}{D_{45,40}}=v\left(1-p_{45} p_{40}\right)=0,00379 \\
& 1,5 \times \frac{C_{45,40}}{D_{45,40}}=1,5 \times 0,00379=0,00569
\end{aligned}
$$

Premi kotor pada contoh polis adalah Rp.5.000.000,00 sehingga dapat disimpulkan bahwa premi kotor lebih besar dari $1,5 \times \frac{C_{45,40}}{D_{45,40}}$. Berdasarkan hasil perhitungan kedua premi 
tahunan dapat disimpulkan bahwa $P_{45,40: \bar{n} \mid}<$ ${ }_{20} P_{45,40}$ dan premi kotor $>1,5 \times \frac{C_{45,40}}{D_{45,40}}$ sehingga dalam contoh kasus tersebut dapat menggunakan metode New Jersey.

Akan dihitung anuitas akhir asuransi jiwa joint life dengan $n=19$ untuk menentukan nilai $\beta^{J}$ diperoleh :

$$
\begin{aligned}
& \begin{aligned}
a_{45,40: \overline{19 \mid}} & =\sum_{m=1}^{19} v^{m}{ }_{m} p_{45,40} \\
& =0,96239+0,92572+\ldots+0,40760 \\
& =12,29303
\end{aligned} \\
& \beta^{J}=P_{45,40: \overline{30 \mid}}+\frac{P_{45,40: 30 \mid}-\frac{C_{45,40}}{D_{45,40}}}{a_{45,40: 19}} \\
& =0,02668+\frac{0,02668-0,00379}{12,29303} \\
& =0,02854
\end{aligned}
$$

Diketahui bahwa dengan menerapkan metode New Jersey, cadangan premi pada akhir tahun pertama adalah nol. Perhitungan cadangan premi menggunakan metode New Jersey berdasarkan metode prospektif pada tahun kedua adalah:

$$
\begin{aligned}
{ }_{2} V_{45,40: \overline{30 \mid}=} & A_{47,42: \overline{28 \mid}}-\left(\beta^{J}-P_{45,40: \overline{30 \mid}}\right) \\
& \ddot{a}_{47,42: \overline{18 \mid}}-P_{45,40: \overline{30 \mid}} \ddot{a}_{47,42: \overline{28 \mid}} \\
= & 0,46783-(0,02854-0,02668) \\
& 12,68012-0,02668(15,73689) \\
= & 0,02439
\end{aligned}
$$

Pada tahun ketiga, cadangan preminya adalah :

$$
\begin{aligned}
{ }_{3} V_{45,40: \overline{30 \mid}=} & A_{48,43: \overline{27 \mid}}-\left(\beta^{J}-P_{45,40: \overline{30 \mid}}\right) \\
& \ddot{a}_{48,43: \overline{17 \mid}}-P_{45,40: \overline{30 \mid}} \ddot{a}_{48,43: \overline{27 \mid}} \\
= & 0,48160-(0,02854-0,02668) \\
& 12,15010-0,02668(15,32985) \\
= & 0,05000
\end{aligned}
$$

Pada tahun keempat, cadangan preminya adalah:

$$
\begin{aligned}
{ }_{4} V_{45,40: \overline{30 \mid}=} & A_{49,44: \overline{26 \mid}}-\left(\beta^{J}-P_{45,40: \overline{30 \mid}}\right) \\
& \ddot{a}_{49,44: \overline{16 \mid}}-P_{45,40: \overline{30 \mid}} \ddot{a}_{49,44: \overline{26 \mid}} \\
= & 0,49557-(0,02854-0,02668) \\
& 11,60667-0,02668(14,91664) \\
= & 0,07601
\end{aligned}
$$

Pada tahun kelima, cadangan preminya adalah :

$$
\begin{aligned}
{ }_{5} V_{45,40: \overline{30 \mid}=} & A_{50,45: \overline{25 \mid}}-\left(\beta^{J}-P_{45,40: \overline{30 \mid}}\right) \\
& \ddot{a}_{50,45: \overline{15 \mid}}-P_{45,40: \overline{30 \mid}} \ddot{a}_{50,45: \overline{25 \mid}} \\
= & 0,50975-(0,02854-0,02668) \\
& 11,04919-0,02668(14,49725) \\
= & 0,10242
\end{aligned}
$$

Cara yang sama digunakan untuk menghitung cadangan premi pada tahun keenam hingga tahun ke 30.

\subsubsection{Cadangan Cara Prospektif dengan Menerapkan Metode New Jersey dan Hukum De Moivre}

Nilai tunai anuitas hidup berjangka awal asuransi jiwa joint life selama $n=30$ dan $n=$ 20 tahun menggunakan hukum De Moivre:

$$
\begin{aligned}
\ddot{a}_{45,40: \overline{30 \mid}} & =\sum_{m=0}^{29} v^{m}\left(\frac{111-45-m}{111-45}\right)\left(\frac{111-40-m}{111-40}\right) \\
& =1+0,93814+\cdots+0,12228 \\
& =13,24609 \\
\ddot{a}_{45,40: \overline{20 \mid}} & =\sum_{m=0}^{19} v^{m}\left(\frac{111-45-m}{111-45}\right)\left(\frac{111-40-m}{111-40}\right) \\
& =1+0,93814+\cdots+0,27129 \\
& =11,43397
\end{aligned}
$$

Nilai premi tunggal dan tahunan asuransi jiwa joint life selama 30 tahun menggunakan hukum De Moivre diperoleh:

$$
\begin{aligned}
& A_{45,40 \overline{30 \mid}}=1-d\left(\ddot{a}_{45,40: \overline{30 \mid}}\right) \\
&=1-0,03382(13,24609) \\
&=0,55206 \\
& P_{45,40: \overline{30 \mid}}=\frac{A_{45,40 \overline{30 \mid}}}{\ddot{a}_{45,40: \overline{30 \mid}}}=0,04168
\end{aligned}
$$

Premi tunggal untuk asuransi joint life seumur hidup menggunakan hukum De Moivre diperoleh :

$$
\begin{aligned}
A_{45,40}= & \sum_{m=0}^{\infty} v^{m+1}\left(\frac{111-45-m}{111-45}\right)\left(\frac{111-40-m}{111-40}\right) \\
& \left(1-\left(\frac{111-45-m-1}{111-45-m}\right)\left(\frac{111-40-m-1}{111-40-m}\right)\right) \\
= & (0,02804)+(0,02669)+\cdots \\
= & 0,51413
\end{aligned}
$$

Premi tahunan dengan masa pembayaran 20 kali untuk asuransi joint life seumur hidup menggunakan hukum De Moivre diperoleh:

$$
{ }_{20} P_{45,40}=\frac{A_{45,40}}{\ddot{a}_{45,40: \overline{: 0 \mid}}}=\frac{0,51413}{11,43397}=0,04496
$$

Nilai tunai premi bersih lanjutan asuransi jiwa joint life disesuaikan pada tahun pertama menggunakan hukum De Moivre diperoleh:

$$
\alpha^{J}=\frac{C_{45,40}}{D_{45,40}}=0,02804
$$




$$
1,5 \times \frac{C_{45,40}}{D_{45,40}}=1,5 \times 0,02804=0,04206
$$

Premi kotor pada contoh polis adalah Rp.5.000.000,00 maka premi kotor lebih besar dari $1,5 \times \frac{C_{45,40}}{D_{45,40}}$. Hasil perhitungan kedua premi tahunan menunjukkan bahwa $P_{45,40: \overline{n \mid}}<$ ${ }_{20} P_{45,40}$ dan premi kotor $>1,5 \times \frac{C_{45,40}}{D_{45,40}}$ sehingga dalam contoh kasus tersebut dapat menggunakan metode New Jersey.

Anuitas akhir asuransi jiwa joint life dengan $n=19$ menggunakan hukum De Moivre diperoleh :

$$
\begin{aligned}
a_{45,40: \overline{19 \mid}} & =\sum_{m=1}^{19} v^{m}\left(\frac{111-45-m}{111-45}\right)\left(\frac{111-40-m}{111-40}\right) \\
& =0,93814+0,87972+\cdots+0,27128 \\
& =10,43397
\end{aligned}
$$

Nilai $\beta^{J}$ yang menerapkan hukum $D e$ Moivre sebagai berikut :

$$
\begin{aligned}
\beta^{J} & =P_{45,40: \overline{30 \mid}}+\frac{P_{45,40: \overline{30 \mid}}-\alpha^{J}}{a_{45,40: \overline{19 \mid}}} \\
& =0,04168+\frac{0,04168-0,02804}{10,43397} \\
& =0,04168+0,00130 \\
& =0,04298
\end{aligned}
$$

Diketahui bahwa dengan menerapkan metode New Jersey, cadangan premi pada akhir tahun pertamanya adalah nol.

Perhitungan cadangan premi asuransi joint life menggunakan metode New Jersey berdasarkan metode prospektif pada tahun kedua dan menerapkan hukum De Moivre diperoleh:

$$
\begin{aligned}
{ }_{2} V_{45,40: \overline{30 \mid}=} & A_{47,42: \overline{28 \mid}}-\left(\beta^{J}-P_{45,40: \overline{30 \mid}}\right) \\
& \ddot{a}_{47,42: \overline{18 \mid}}-P_{45,40: \overline{30 \mid}} \ddot{a}_{47,42: \overline{28 \mid}} \\
= & 0,56532-(0,04298-0,04168) \\
& 10,79411-0,04168(12,85398) \\
= & 0,01549
\end{aligned}
$$

Pada tahun ketiga, cadangan preminya adalah :

$$
\begin{aligned}
{ }_{3} V_{45,40: \overline{30 \mid}=} & A_{48,43: \overline{27 \mid}}-\left(\beta^{J}-P_{45,40: \overline{30 \mid}}\right) \\
& \ddot{a}_{48,43: \overline{17 \mid}}-P_{45,40: 30 \mid} \ddot{a}_{48,43: \overline{27 \mid}} \\
= & 0,57232-(0,04298-0,04168) \\
& 10,44924-0,04168(12,64691) \\
= & 0,03157
\end{aligned}
$$

Pada tahun keempat, cadangan preminya adalah:

$$
{ }_{4} V_{45,40: \overline{30 \mid}}=A_{49,44: \overline{26 \mid}}-\left(\beta^{J}-P_{45,40: \overline{30 \mid}}\right)
$$

$$
\begin{aligned}
& \ddot{a}_{49,44: \overline{16 \mid}}-P_{45,40: \overline{30 \mid}} \ddot{a}_{49,44: \overline{26} \mid} \\
= & 0,57960-(0,04298-0,04168) \\
& 10,08603-0,04168(12,43179) \\
= & 0,04829
\end{aligned}
$$

Pada tahun kelima, cadangan preminya adalah :

$$
\begin{aligned}
{ }_{5} V_{45,40: \overline{30 \mid}=} & A_{50,45: \overline{25 \mid}}-\left(\beta^{J}-P_{45,40: \overline{30 \mid}}\right) \\
& \ddot{a}_{50,45: \overline{15 \mid}}-P_{45,40: \overline{30 \mid}} \ddot{a}_{50,45: \overline{25 \mid}} \\
= & 0,58716-(0,04298-0,04168) \\
& 9,70303-0,04168(12,20808) \\
= & 0,06568
\end{aligned}
$$

Cara yang sama digunakan untuk menghitung cadangan premi pada tahun keenam hingga tahun ke 30.

Tabel 1. Hasil Perhitungan Cadangan Premi Asuransi Jiwa Joint Life Berdasarkan Hukum De Moivre dan Tanpa Hukum De Moivre

\begin{tabular}{|c|c|c|}
\hline $\begin{array}{c}\text { Tah } \\
\text { un } \\
\text { ke- }\end{array}$ & $\begin{array}{c}\text { Cadangan Premi } \\
\text { Tanpa Hukum }\end{array}$ & $\begin{array}{c}\text { Cadangan Premi } \\
\text { Dengan Hukum }\end{array}$ \\
\hline 1 & 0 & 0 \\
2 & 0.024395040387577 & 0.0154946814869850 \\
3 & 0.050004600712109 & 0.0315785181420223 \\
4 & 0.076014456765895 & 0.0482926624214619 \\
5 & 0.102422861076751 & 0.0656820410653948 \\
6 & 0.129189929933458 & 0.0837957644763958 \\
7 & 0.156266983506554 & 0.1026875871610912 \\
8 & 0.183631275997607 & 0.1224164264773075 \\
9 & 0.211316843391467 & 0.1430469480883547 \\
10 & 0.239364572309215 & 0.1646502278924980 \\
11 & 0.267822989392983 & 0.1873045018111170 \\
12 & 0.296741857096413 & 0.2110960167340460 \\
13 & 0.326160291366459 & 0.2361199981969124 \\
14 & 0.356136237147265 & 0.2624817530789035 \\
15 & 0.386752867895730 & 0.2902979288539462 \\
16 & 0.418100470439856 & 0.3196979548195837 \\
17 & 0.450290124670862 & 0.3508256954097655 \\
18 & 0.483439007177314 & 0.3838413513496476 \\
19 & 0.517669990116459 & 0.4189236512567573 \\
20 & 0.553099687839916 & 0.4562723846157028 \\
21 & 0.587877307731587 & 0.4947009627885255 \\
22 & 0.624024194022844 & 0.5357566856284288 \\
23 & 0.661756903042537 & 0.5797099583217168 \\
24 & 0.701249178730358 & 0.6268656571720465 \\
25 & 0.742863616225482 & 0.6775683454502794 \\
26 & 0.786944831516793 & 0.7322084114508199 \\
27 & 0.833985071153733 & 0.7912293171502148 \\
28 & 0.884539373176961 & 0.8551361898952551 \\
29 & 0.939505195430077 & 0.9245060452512661 \\
30 & 1 & 1 \\
\hline
\end{tabular}




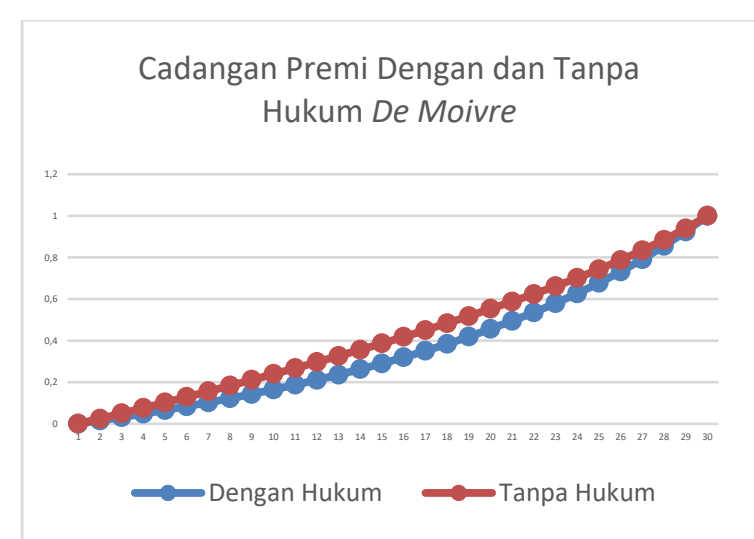

Gambar 1. Hasil Perhitungan Cadangan Premi Asuransi Joint Life Dengan dan Tanpa Penerapan Hukum De Moivre

Tabel 1 dan Gambar 1 menunjukkan nilai cadangan premi untuk asuransi jiwa joint life, dapat terlihat bahwa nilai cadangan premi asuransi jiwa joint life yang menerapkan hukum De Moivre menghasilkan nilai lebih kecil dibandingkan nilai cadangan premi asuransi joint life tanpa menerapkan hukum De Moivre.

\section{KESIMPULAN DAN SARAN}

Berdasarkan pembahasan sebelumnya maka dapat diperoleh cadangan premi yang menerapkan metode New Jersey dan hukum De Moivre pada asuransi joint life yaitu :

$$
\begin{aligned}
{ }_{t} V_{x y: \bar{n} \mid}= & A_{x+t, y+t: \overline{n-t \mid}}-\left(\beta^{J}-P_{x y: \overline{n \mid}}\right) \\
& \ddot{a}_{x+t, y+t: \overline{20-t \mid}}-P_{x y: \overline{n \mid}} \ddot{a}_{x+t, y+t: \overline{n-t \mid}}
\end{aligned}
$$

dengan :

$$
\begin{aligned}
& A_{x+t, y+t: \overline{n-t \mid}}=1-d\left(\sum_{m=0}^{n-t-1} v^{m}\left(\frac{\omega-x+t-m}{\omega-x+t}\right)\left(\frac{\omega-y+t-m}{\omega-y+t}\right)\right) \\
& \beta^{J}=\frac{1-d\left(\sum_{m=0}^{n-1} v^{m}\left(\frac{\omega-x-m}{\omega-x}\right)\left(\frac{\omega-y-m}{\omega-y}\right)\right)}{\sum_{m=0}^{n-1} v^{m}\left(\frac{\omega-x-m}{\omega-x}\right)\left(\frac{\omega-y-m}{\omega-y}\right)}+ \\
& \\
& \frac{\left\{\frac{1-d\left(\sum_{m=0}^{n-1} v^{m}\left(\frac{\omega-x-m}{\omega-x}\right)\left(\frac{\omega-y-m}{\omega-y}\right)\right)}{\sum_{m=0}^{n-1} v^{m}\left(\frac{\omega-x-m}{\omega-x}\right)\left(\frac{\omega-y-m}{\omega-y}\right)}\right\}}{\sum_{m=1}^{19} v^{m}\left(\frac{\omega-x-m}{\omega-x}\right)\left(\frac{\omega-y-m}{\omega-y}\right)} \\
&-\frac{v\left(1-\frac{\omega-x-1}{\omega-x} \frac{\omega-y-1}{\omega-y}\right)}{\sum_{m=1}^{19} v^{m}\left(\frac{\omega-x-m}{\omega-x}\right)\left(\frac{\omega-y-m}{\omega-y}\right)} \\
& P_{x y: \bar{n} \mid}=\frac{1-d\left(\sum_{m=0}^{n-1} v^{m}\left(\frac{\omega-x-m}{\omega-x}\right)\left(\frac{\omega-y-m}{\omega-y}\right)\right)}{\sum_{m=0}^{n-1} v^{m}\left(\frac{\omega-x-m}{\omega-x}\right)\left(\frac{\omega-y-m}{\omega-y}\right)} \\
& \ddot{a}_{x+t, y+t: \overline{20-t \mid}}=\sum_{m=0}^{20-t-1} v^{m}\left(\frac{\omega-x+t-m}{\omega-x+t}\right)\left(\frac{\omega-y+t-m}{\omega-y+t}\right)
\end{aligned}
$$

$\ddot{a}_{x+t, y+t: \overline{n-t \mid}}=\sum_{m=0}^{n-t-1} v^{m}\left(\frac{\omega-x+t-m}{\omega-x+t}\right)\left(\frac{\omega-y+t-m}{\omega-y+t}\right)$

Perhitungan cadangan premi asuransi joint life 30 tahun dengan metode New Jersey dan menerapkan hukum De Moivre dari awal tahun selalu menghasilkan nilai lebih kecil dibandingkan nilai cadangan premi tanpa menerapkan hukum De Moivre namun pada akhir waktu kontrak, keduanya bernilai sama sesuai dengan jumlah uang pertanggungan.

Disarankan dalam penelitian selanjutnya menerapkan metode lain seperti metode Kanada, metode Zillmer dan metode-metode lainnya serta dapat dikembangkan dengan menggunakan hukum yang lain seperti hukum Weibull, hukum Makeham dan hukum Gompertz.

\section{DAFTAR PUSTAKA}

Bowers, N. L., Gerber, H. U., Hickman, J. C., Jones, D. A., \& Nesbitt, C. J. 1997. Actuarial Mathematics. Schaumburg Illinois: The Society of Actuaries.

Fibrianti, V. L. 2016. Penerapan Hukum De Moivre pada Metode New Jersey dalam Penentuan Nilai Cadangan Asuransi Jiwa Dwiguna. Skripsi. FST, Matematika, Universitas Islam Negeri Maulana Malik Ibrahim, Malang.

Finan, M. B. 2011. A Reading of the Theory of Life Contingency Models: A Preparation for Exam MLC/3L. Arkansas Tech university, Arkansas.

Futami, T. 1994. Matematika Asuransi Jiwa Bagian II. Herliyanto G, penerjemah. Tokyo (JP): Oriental Life Insurance Cultural Development Center. Terjemahan dari: Seime Hoken Sugaku Gekan ("92 Revision).

Hasrullah. 2019. Penentuan Cadangan Premi untuk Asuransi Joint Life Dwiguna Murni Berjangka dengan Metode Retrospektif. Skripsi. FST, Matematika, Universitas Islam Negeri Alauddin, Makassar.

Sembiring, R. K. 1986. Buku Materi Pokok Asuransi I Modul 1-5. Jakarta: Karunika.

Tewo, J. L., Widana, I Nyoman, \& Oka, T. B. 2018. Penentuan Cadangan Premi dengan Metode New Jersey pada Asuransi Joint Life. E-Jurnal Matematika, 7(3), 226-231. 